\title{
INFORMAÇÃO, PATRIMÔNIO E MEMÓRIA INSTITUCIONAL: A EXPERIÊNCIA DO CURSO DE ESPECIALIZAÇÃO EM CULTURA E ARTE BARROCA EM OURO PRETO
}

\author{
Neide Nativa \\ Mestranda em Ciência da Informação - UFMG \\ neidenativa@hotmail.com \\ Alcenir Soares dos Reis \\ Doutora em Ciência da Informação \\ Professora da ECI/UFMG \\ alcenirsoares@gmail.com
}

\section{Resumo}

\begin{abstract}
Este artigo corresponde ao resultado parcial da pesquisa e análise sobre o Curso de Especialização em Cultura e Arte Barroca (CECAB), oferecido pela Universidade Federal de Ouro Preto. O aporte teórico foi fundamentado em três pilares: a questão conceitual de Patrimônio e Cultura Barroca, fundamental para o entendimento do objeto da pesquisa, a constituição da Memória, enquanto espaço de sedimentação do saber e a Ciência da Informação, como suporte para a construção e interlocução das narrativas de memória. No recorte aqui apresentado o objetivo consistiu em investigar, analisar e elucidar as informações sobre o acervo de monografias de conclusão de curso produzidas pelos alunos, com vistas a apreender o seu papel e contribuição enquanto instância educativa e de produção de conhecimentos na temática do patrimônio cultural. A metodologia consistiu na identificação das monografias e de seus autores, no estudo da abrangência temática dos assuntos pesquisados e a investigação sobre as dissertações, teses e livros que tiveram as suas origens a partir de pesquisas iniciadas na elaboração das monografias. Os resultados mostraram que o curso produziu duzentas monografias com abordagens diversas sobre a cultura e arte do Período Colonial brasileiro, sendo que trinta e seis delas tiveram continuidade como pesquisa de mestrado, doutorado ou publicação de livro. A pesquisa evidenciou a relevância do CECAB para a formação de especialistas e na produção de conhecimento científico sobre o patrimônio cultural brasileiro, contribuindo para ampliar as reflexões neste campo específico.
\end{abstract}

Palavras-chave: Informação e memória. Patrimônio cultural. Memória institucional. Conhecimento científico. Cultura e Arte barroca.

\section{INTRODUÇÃO}

Este artigo corresponde ao resultado parcial de uma pesquisa que se encontra em curso, tendo como objetivo analisar o Curso de Especialização em Cultura e Arte Barroca (CECAB), oferecido pelo Instituto de Filosofia, Artes e Cultura (IFAC) da Universidade Federal de Ouro Preto (UFOP). $\mathrm{O}$ trabalho, de caráter mais abrangente, tendo como centralidade a questão informacional, com ênfase na memória institucional do CECAB, buscou recuperar e apreender a relevância do curso para o campo do patrimônio brasileiro, em termos de formação de recursos humanos especializados e de produção de conhecimentos.

Sob uma perspectiva histórica vale indicar que o curso funcionou por vinte e oito anos, de 1985 a 2013, e foi responsável pela formação de profissionais especialistas nas questões relativas à cultura e a arte do Período Colonial brasileiro, temática intrinsecamente relacionada ao patrimônio cultural. Em termos de produção científica foram produzidas 200 (duzentas) monografias, cujas pesquisas que abrangem diversos aspectos da temática do Barroco, algumas editadas como livros ou convertidas, em etapas posteriores, a trabalhos correspondentes ao nível de mestrado e/ou 
doutorado, além de artigos científicos publicados em periódicos nacionais e estrangeiros. Em 2013 o curso foi suspenso por razões legais, justificadas por decisão de impedimento em relação à cobrança de pagamento por cursos de pós-graduação nas universidades federais, fato que provocou a interrupção de uma iniciativa pioneira, responsável pela formação de profissionais qualificados e de produção de conhecimentos relevantes para a área do patrimônio cultural brasileiro.

A pesquisa, no recorte aqui apresentado, teve como objetivo principal investigar, analisar e elucidar as informações sobre o acervo de monografias de conclusão de curso produzidas pelos alunos, buscando apreender a sua relevância e contribuição enquanto instância educativa e de produção de conhecimentos na temática do patrimônio cultural.

O desenvolvimento desta pesquisa se deu em duas etapas: a primeira consistiu na busca e na identificação das monografias no acervo bibliográfico da UFOP, a abordagem temática dos assuntos e a dos autores. Na segunda etapa realizamos uma pesquisa sobre os autores das monografias, a partir de seus currículos na Plataforma Lattes, bases de dados digitais, catálogos e em repositórios institucionais, para identificar as dissertações, teses e livros que tiveram as suas origens a partir de pesquisas iniciadas para a elaboração da monografia de conclusão do CECAB.

Optamos por buscar o aporte teórico em três pilares que nortearam os rumos da investigação, sendo eles: a questão conceitual de Patrimônio e Cultura Barroca, fundamental para o entendimento do objeto de pesquisa, a constituição da Memória, enquanto espaço de sedimentação do saber sob o ponto de vista coletivo, social, individual e, em especial a memória institucional, e o aporte da Ciência da Informação, na perspectiva da construção e interlocução das narrativas de memória.

\section{INFORMAÇÃO, MEMÓRIA E PATRIMÔNIO: CONFLUÊNCIAS}

${ }^{11}$ CAPURRO, R. Epistemologia e Ciência da Informação. In: ENANCIB, 5, 2003, Belo Horizonte. Conferência de abertura. Belo Horizonte: ECI/UFMG, 2003.
Em decorrência da temática, das questões problematizadas e dos objetivos que instigaram a proposição desta pesquisa, buscamos o apoio teórico na literatura da área das Ciências Sociais, principalmente da Ciência da Informação e da História, tendo em foco que a informação é um elemento que está sempre presente e evidente nas relações humanas e sociais.

\subsection{A INFORMAÇÃO COMO PRODUTO SOCIAL}

A confluência entre informação e memória é o fluxo condutor que perpassa por esses três pilares, a Informação, a Memória e o Patrimônio Cultural, presente em todas as etapas do trabalho investigativo, pois se trata de recuperar informações relevantes que possam elucidar o papel de um elemento - no caso, o Curso de Especialização em Cultura e Arte Barroca - na tentativa de constituir/estabelecer uma memória institucional do mesmo, como proposto nos objetivos da pesquisa. Sendo assim, priorizamos apreender e discutir a dimensão da informação em sua perspectiva social, de acordo com o campo teórico da Ciência da Informação.

Dessa forma, optamos, primeiramente, por retomar algumas considerações concernentes aos estudos que tratam a informação, e também a memória, como fenômenos socioculturais, parte do mundo das relações sociais, considerando que o objeto de estudo é um curso de pós-graduação, um evento institucional, um espaço de geração e socialização de conhecimentos, portanto, um espaço social, de relações sociais, constituído principalmente por pessoas, por indivíduos.

Expondo o seu ponto de vista sobre o conceito de informação como acontecimento social, Capurro ${ }^{1}$ explicita que "a informação é uma dimensão da existência humana, algo que permeia a convivência social, o que significa que a informação e o conhecimento tratam de criação humana, constituindo-se como fenômeno da esfera cultural" CAPURRO (2003, apud CABRAL, 2007, p.37). É nessa 
ótica, assumida pelas Ciências Sociais e Humanas, que pretendemos utilizar o termo informação: como um produto social resultante da interação entre pessoas, das relações humanas, nos espaços de convivência social, de troca de experiências, onde a informação é potencializada e transformada em conhecimento.

Para Cardoso (1994), toda informação é social e quando é tratada como uma área de estudos da Ciência da Informação ela se torna um recurso pedagógico que possibilita identificar o conhecimento e analisar metodologias acerca da produção, organização, disseminação, consumo e incorporação da informação, enfatizando a diversidade de processos e relações que ocorrem no cotidiano dos indivíduos, segmentos, classes e instituições sociais. Segundo a pesquisadora, o objeto de estudo da área de Informação Social, onde se respalda a presente pesquisa, deve ser apropriado tendo como referência as "dimensões de historicidade dos sujeitos cognoscentes", a "totalidade dos fenômenos sociais" e a "tensionalidade constante que está presente na sociedade" (CARDOSO, 1994, p. 111).

Refletindo sobre as correntes teóricas da Ciência da Informação, mais precisamente sobre o conceito de informação, e consoante com a teoria crítica, Araújo (2009, p. 196) afirma que "as dimensões da tensionalidade e da historicidade se tornaram as mais relevantes para a explicação da realidade humana". Nesta mesma perspectiva e de acordo com Reis (2015, p. 109), quando analisamos a informação em sua inserção no contexto social e a partir de uma ótica crítica, "torna-se evidente não ser possível entendê-la fora de sua inserção histórica, em termos de uma apreensão de totalidade e de vê-la também em seus aspectos intrinsecamente contraditórios". Sobre a relação entre os campos da informação e do patrimônio cultural, essa pesquisadora diz que a área da informação pode ser um recurso para apreender e consolidar as experiências vivenciadas por determinados grupos sociais, como forma de preservar memórias e o patrimônio cultural. Nas palavras de Reis,

[...] é preciso destacar que as dimensões da informação são relevantes, haja vista que, através delas, também é possível estabelecerse o vínculo com a preservação de fazeres e memórias, principalmente quando se trata do patrimônio imaterial, permitindo, portanto, recuperar processos que por ausência de conhecimento seriam ignorados em sua preciosidade (REIS, 2015, p. 118)

Em função dos pontos de vista anteriormente indicados, esta pesquisa, que na sua totalidade visa resgatar parte da memória institucional de um curso de pós-graduação de uma universidade pública brasileira, através de sua produção científica, está em conformidade com o campo teórico da Ciência da Informação, especialmente no enfoque da Informação Social, e em sua dinâmica e análise traduz às categorias da historicidade, de tensionalidade e de totalidade, colocadas pelos autores que deram suporte teórico nesta perspectiva da investigação.

\subsection{A MEMÓRIA E SUAS VERTENTES}

Em relação à questão da memória, pois estamos aqui analisando parte da memória do CECAB, em especial a sua produção de conhecimentos científicos, formalizada nas monografias, optamos por utilizar as concepções de memória individual, coletiva e memória institucional. Para Halbwachs (2006, p. 23) "não é o indivíduo em si ou alguma entidade social que recorda. Ninguém pode se lembrar realmente a não ser em sociedade, pela presença ou pela evocação, portanto, recorrendo aos outros ou as suas obras." No entendimento deste autor a memória, no sentido estrito, é em si mesma, um ato coletivo: "de bom grado diríamos que cada memória individual é um ponto de vista sobre a memória coletiva, que este ponto de vista muda segundo o lugar que ali ocupo e que esse mesmo lugar muda segundo as relações que mantenho com outro ambientes" (HALBWACHS, 2006, p.68). Na sua proposição, o autor ressalta o papel do grupo para a construção da memória coletiva, e diz que ela é o grupo visto de dentro. Para ele "toda memória coletiva tem como suporte um grupo limitado no tempo e no espaço. Não podemos reunir em um único painel a totalidade dos eventos passados, a não ser tirando-o da memória dos grupos que guardam sua lembrança." (HALBWACHS, 2006, p.106).

Nesta mesma direção, Bosi (1979, p. 399), no seu estudo sobre memória social, mais 
precisamente sobre a propagação de conhecimentos por meio do que ficou registrado na memória, diz que "aquilo que se viu e se conheceu bem, aquilo que custou anos de aprendizado... passa (ou deveria passar) à outra geração como um valor." A autora reforça a relevância do grupo na construção da memória social:

Quando um grupo trabalha intensamente em conjunto, há uma tendência de criar esquemas coerentes de narração e de interpretação dos fatos, verdadeiros "universos de discursos", "universos de significados", que dão ao material de base uma formação histórica própria, uma versão consagrada dos acontecimentos (BOSI, 1979, p. 27).

Jacques Le Goff (2003 p. 471), afirma que a memória só pode ser validada se for compreendida como fonte de informação histórica, contextualizada no tempo, no espaço e no sentimento de continuidade, com ligação entre o presente, o passado e o futuro, "a memória, na qual cresce a história, que por sua vez a alimenta, procura salvar o passado para servir ao presente e ao futuro."

Ainda sobre a questão da memória, agregamos a discussão de memória institucional, no sentido mais abrangente, que é o ato de instituir, de estabelecer, de ver de outra maneira a instituição e sua memória. Bourdieu, em seu texto Os ritos de instituição, diz:

[...] instituir é consagrar, ou seja, sancionar e santificar um estado de coisas, uma ordem estabelecida... uma diferença (preexistente ou não) fazendo-a conhecer e reconhecer, fazendo-a existir enquanto diferença social, conhecida e reconhecida pelo agente investido e pelos demais." (BOURDIEU, 2008, p. 99).

Continuando no mesmo raciocínio o autor afirma que instituir é "atribuir uma essência, uma competência... é dar uma definição social, uma identidade..." (BOURDIEU, 2008, p. 100). Transpondo essa abordagem conceitual para o âmbito das relações sociais, dos grupos sociais, vemos que a instituição é um processo dinâmico e coletivo, onde diversas forças se confluem, como um movimento que torna visível um conjunto de saberes que circulam, se instituem ou reinstituem-se.
Thiesen (1997, p. 100) endossa a tese de Bourdieu, quando diz que "as instituições são obras dos indivíduos porque são eles que agem... se quisermos falar de memória institucional é fundamental que possamos identificar as condições históricas que tornaram possível a atualização das instituições, quaisquer que sejam, num determinado campo social." No que se refere à institucionalização da Ciência da Informação, a autora adverte:

Quando analisamos a instituição científica ou o saber científico, é necessário que façamos a diferença entre ciência feita e ciência sendo feita, ou a ciência em ação. É preciso mostrar os bastidores do fazer científico, as práticas cotidianas, os microprocessos vistos caso a caso. Isso só é possível na medida em que possamos abordar a construção de nosso objeto como processo, com suas vicissitudes, seus insucessos e suas possibilidades, buscando sua emergência na sociedade, bem como suas mutações no tempo. (THIESEN, 1997, p. 92).

Desta forma é possível colocar que a perspectiva da autora se aproxima mais da questão colocada no âmbito desta pesquisa, ou seja, um curso vinculado a uma instituição científica, com toda a sua carga de conflitos, de disputas de poder, de resistências, mas também de sucesso, de avanços, de contribuição e participação no campo social.

Assim, para Thiesen (1997, p. 154) a memória é essencial para o funcionamento das instituições, pois elas funcionam em rede no campo social, e "as informações relevantes para a recuperação da memória institucional devem ser, por isso, buscadas não apenas nos materiais e fontes internas, mas fora dos muros institucionais." E acrescenta: "A memória institucional está em permanente elaboração, pois é função do tempo." Sendo assim, as formulações dos autores citados anteriormente, fornece os elementos e os subsídios necessários para a compreensão do CECAB/UFOP.

\subsection{PATRIMÔNIO CULTURAL E A CULTURA BARROCA}

Somando-se às discussões anteriores, retoma-se a questão do patrimônio cultural e a cultura barroca, dois tópicos que foram 
incorporados ao referencial teórico para o entendimento e análise dos elementos desta pesquisa, ou seja, objeto desta pesquisa, o $\mathrm{CECAB}$, que capacitou e qualificou um grande número de profissionais para atuarem, direta ou indiretamente, no campo do patrimônio cultural brasileiro.

Por muito tempo o conceito de patrimônio cultural era associado ao conjunto de monumentos edificados e antigos, que deveriam ser preservados por serem considerados como obras de arte, ou por terem feito parte da história, documentados em registros históricos. Esse conceito refletia a imagem construída ao longo dos anos por interesses do Estado, que é o responsável pela política de patrimônio do país. Essa concepção vem sendo modificada, reconstruída e ampliada $^{2}$, através da incorporação do conceito de patrimônio imaterial ou intangível, que trata o patrimônio "além da pedra e da $\mathrm{cal}^{3}$ ", expressão utilizada pelos pesquisadores e profissionais da área quando se refere ao patrimônio material.

Quando se trata de patrimônio cultural está se referindo ao conjunto de tudo que tem significação, aquilo que tem sentido social, não importando se esse patrimônio é algo materializado (visível) ou simplesmente manifestações da cultura. Para Araripe (2004, p. 4), "é necessário lembrar que existe um patrimônio que se encontra nas práticas cotidianas e é preciso que também seja preservado, isto é, apresentado como tal e com valor social." De acordo com a autora as

${ }^{2}$ A Constituição Federal de 1988, em seu Artigo $\underline{216}$, ampliou o conceito de patrimônio estabelecido pelo Decreto-lei no 25 , de 30 de novembro de 1937 , substituindo a nominação Patrimônio Histórico e Artístico, por Patrimônio Cultural Brasileiro. Essa alteração incorporou o conceito de referência cultural e a definição dos bens passíveis de reconhecimento, sobretudo os de caráter imaterial... Nessa redefinição promovida pela Constituição, estão as formas de expressão; os modos de criar, fazer e viver; as criações científicas, artísticas e tecnológicas; as obras, objetos, documentos, edificações e demais espaços destinados às manifestações artístico-culturais; os conjuntos urbanos e sítios de valor histórico, paisagístico, artístico, arqueológico, paleontológico, ecológico e científico. Fonte: Site do IPHAN: http://portal.iphan.gov.br/pagina/detalhes/218. Acesso em: 01/06/2016. exigências contemporâneas fizeram com que se ampliasse a designação "patrimônio histórico e artístico" para "patrimônio cultural", levando-se em consideração toda a produção humana como um bem cultural.

A origem das políticas preservacionistas do patrimônio cultural brasileiro esta intrinsecamente relacionada à Cultura e à Arte barroca, tendo em vista que as primeiras ações por parte do Estado se deram a partir da necessidade de preservação das cidades ou sítios históricos, que abrigam as reminiscências do Período Colonial, caracterizado pelo estilo Barroco. A ideia de Patrimônio Nacional só emergiu na década de 20, a partir da busca de uma identidade própria para o Brasil, por meio de iniciativas de intelectuais e artistas, que redescobriram as cidades históricas mineiras ${ }^{4}$. A primeira lei de proteção aos bens culturais foi aprovada no país em 1933 e elevou Ouro Preto à categoria de "monumento nacional". Posteriormente, foi criada pelo governo de Getúlio Vargas a Inspetoria de Monumentos Nacionais, projetada para atuar em todos os centros históricos do país, entre os quais Salvador, Olinda e Ouro Preto. O tema do patrimônio entrou definitivamente na pauta das discussões do poder público, para a criação de uma instituição específica para tratar dos assuntos relativos à preservação da memória brasileira, culminando com a criação do Serviço Nacional do Patrimônio Histórico e Artístico Nacional - SPHAN, em 1937.

3"Pedra e cal" - Termo que faz referência aos tombamentos ocorridos durante o período de atuação de Rodrigo Mello Franco de Andrade no IPHAN (1937 a 1967), constituídos fundamentalmente por bens arquitetônicos.

${ }^{4}$ Ver a respeito: NATAL, Caion Meneguello. Ouro Preto: a construção de uma cidade histórica, 18911993. 2007. 239 f. Dissertação (Mestrado em História) - Instituto de Filosofia e Ciências Humanas, UNICAMP, Campinas, 2007. BRAGA, Vanuza Moreira. Relíquia e exemplo, saudade e esperança: o SPHAN e a consagração de Ouro Preto. 2010. 132 f. Dissertação (Mestrado em História, Políticas e Bens Culturais) Centro de Pesquisa e Documentação de História Contemporânea do Brasil - CPDOC, Fundação Getúlio Vargas, Rio de Janeiro, 2010. 
A partir dessa nova maneira de ver o patrimônio, de uma mudança de paradigma, o tema tornou-se centro dos debates contemporâneos sobre memória e patrimônio, atraindo novas áreas do conhecimento, evidenciando a necessidade de formação de profissionais que tivessem uma visão crítica e mais abrangente, tanto para dar continuidade aos avanços alcançados, como também para atuar nas instâncias de construção de políticas públicas e de preservação do patrimônio cultural brasileiro. Dentro deste quadro, no qual novas exigências se fizeram presentes, tornou-se oportuno apreender qual a contribuição efetiva do CECAB na agregação de novos conhecimentos ao campo de ação do patrimônio cultural brasileiro.

Portanto, foi através do exercício de buscar, coletar, sistematizar e analisar o conjunto de informações sobre a produção de suas pesquisas, é que se tornaram possíveis recompor parte da memória institucional do curso e indicar, com base nesta sistematização histórica, a relevância deste processo de formação para o patrimônio e a cultura.

\section{PERCURSO METODOLÓGICO: ORIENTAÇÕES E DINÂMICA DO PROCESSO}

Dado a característica do objeto desta pesquisa, no caso, a produção científica de um curso de pós-graduação, adotou-se a abordagem qualitativa, em termos da análise das monografias, pois o foco era verificar como e o quanto esta produção contribuiu em termos de conhecimentos científicos para o campo do patrimônio cultural brasileiro. Entretanto, se na análise das monografias a ênfase se fez em termos qualitativos, o processo de pesquisa incorporou recursos estatísticos para facilitar a descrição e a interpretação das informações sobre o mapeamento das temáticas das monografias.

Sendo assim, consideramos que do ponto de vista metodológico, este trabalho foi balizado pelo somatório das abordagens qualitativa e quantitativa, sem prejuízo e em conformidade com as necessidades detectadas no decorrer da pesquisa, tendo como respaldo a conceituação de que método é o "caminho pelo qual se chega a determinado resultado, ainda que esse caminho não tenha sido fixado de antemão de modo refletido e deliberado"

\section{(HESENBERG apud LAKATOS;}

MARCONI, 1989, p. 40).

Quanto à coleta de dados a mesma foi realizada em duas frentes de trabalho de prospecção documental: o levantamento de documentos relativos ao CECAB, localizados nos arquivos do IFAC e a identificação e compilação dos dados correspondentes a 200 (duzentas) monografias de conclusão de curso, que fazem parte do acervo da Biblioteca do IFAC, destacando-se as informações relevantes encontradas nos títulos, resumos, palavras-chaves, conclusões e quando necessário, ao texto integral.

$\mathrm{Na}$ análise correspondente às monografias de conclusão de curso, buscou-se detectar como estas refletem os resultados das pesquisas desenvolvidas pelos alunos, a partir dos conhecimentos adquiridos em sala de aula, nas visitas técnicas, seminários, debates, bem como pelo intercâmbio dialógico entre professores e colegas; soma-se a estes aspectos envolvimento pessoal com a leitura da bibliografia utilizada e recomendada.

De forma concreta, os dados mapeados no contexto da pesquisa, por meio da identificação do montante de monografias e de seus autores, se consolidaram a partir de várias consultas e checagens nas seguintes bases de dados: no Banco de Teses e Dissertações da Capes, na BDTD do IBICT, nos Repositórios Institucionais das Instituições de Ensino Superior brasileiras, e ainda, na Plataforma Lattes. Primeiramente foram identificados os autores a partir da listagem das monografias do CECAB, e em seguida, foi feita a comparação de equivalência dos títulos e das palavras chaves existentes nas três categorias de pesquisas, ou seja, nas monografias, dissertações e teses.

Concluída esta etapa foram feitas as análises dos resumos e sumários das monografias e a equiparação com os demais trabalhos identificados. Recorremos, quando necessário, à leitura dos textos das publicações, como forma de garantir a confiabilidade das informações. A identificação dos títulos de livros que foram publicados a partir das temáticas das monografias foi feita por meio da investigação no Curriculum Lattes dos autores, e equiparados com os resumos das monografias.

Posteriormente, efetivou-se o cotejamento dos dados referentes às monografias buscando 
identificar quais foram transformadas em pesquisas de mestrado, de doutorado, ou ainda, foram publicadas no formato de livros. Esse conjunto de trabalhos científicos é um indicativo de que houve uma progressão ou continuidade da pesquisa a partir do trabalho inicial efetuado para a monografia de conclusão do curso, uma expansão dos conhecimentos apreendidos. Entendemos que este trabalho de pesquisa, envolvendo as duas etapas mencionadas acima e consolidada nos resultados apresentados neste texto, constitui uma síntese da produção e da contribuição científica do CECAB em termos do patrimônio cultural.

Vale ainda esclarecer que, de acordo com a NBR $14724^{5}$, a monografia de conclusão de curso, tratada na categoria de trabalho acadêmico, é definida como um "documento que representa o resultado de estudo, devendo expressar conhecimento do assunto escolhido, que deve ser obrigatoriamente emanado da disciplina, módulo, estudo independente, curso, programa e outros ministrados. Deve ser feito sob a coordenação de um orientador." Para Marconi e Lakatos a monografia é:

Um estudo sobre um tema específico ou particular, com suficiente valor representativo e que obedece a rigorosa metodologia. Investiga determinado assunto não só em profundidade, mas em todos os seus ângulos e aspectos [...]. Contribuição importante, original e pessoal para a ciência (MARCONI e LAKATOS, 1990, p. 205).

As monografias do CECAB encontram-se localizadas no setor de Referência da Biblioteca do IFAC, pois constituem um valioso corpus de pesquisa disponível aos pesquisadores interessados nas temáticas relacionadas à Cultura e Arte barroca. Elas estão devidamente catalogadas, indexadas e acessíveis por meio do catálogo on-line ${ }^{6}$ do Sistema de Bibliotecas da UFOP e são ordenadas por assuntos, classificadas de acordo com os princípios da $\mathrm{CDU}^{7}$. A indexação de assuntos ${ }^{8}$ é feita com o auxílio de instrumentos de tratamento de informação, dado a especificidade e particularidade dos temas abordados, que, dificilmente, são encontrados nos sistemas de controle de vocabulário ${ }^{\mathrm{e}}$ terminologia, utilizados pelo Sistema de Bibliotecas e Informação da UFOP (SISBIN/UFOP).

Vale ainda acrescentar, que no processo de análise dos dados definiu-se identificar a distribuição dos mesmos e apresentar, no contexto dos resultados, as áreas de

em todo o mundo. Fonte: http://www.ibict.br/publicacoes-e-

institucionais/classificacao-decimal-universal-cdu. Acesso em 14/04/2016.

${ }^{8}$ São utilizadas as seguintes publicações para a definição e padronização dos assuntos da área de arte barroca: ÁVILA, Affonso; GONTIJO, J. M. M ; MACHADDO, R. G. Barroco mineiro: glossário de arquitetura e ornamentação. Belo Horizonte: Fundação João Pinheiro, 1980. 220p. ; MARTINS, Judith. Dicionário de artistas e artífices dos séculos XVIII e XIX em Minas Gerais. RJ: IPHAN, 1974. 2 v. ; REAL, Regina M. Dicionário de Belas Artes: termos técnicos e matérias afins. RJ: Fundo de Cultura, 1962, dentre outros.

9 O Sistema de Bibliotecas e Informação SISBIN/UFOP utiliza o controle de vocabulário da Rede Bibliodata (www.bibliodata.ibict.br), da Rede Pergamume da Library ofCongress (http://id.loc.gov/authorities/names) conhecimento humano pode ser dividido em 10 classes principais de conhecimento, e estas, por sua vez, podem ser infinitamente divididas numa hierarquia decimal. É um sistema de classificação consolidado e largamente usado pelas bibliotecas

7 CDU - Classificação Decimal Universal -A Classificação Decimal Universal (CDU) é um sistema internacional de classificação de documentos, cuja base está no conceito de que o 
conhecimento (assuntos), conforme se encontra expresso no Gráfico 1 , apresentado à página $\mathrm{X}$, em função da variedade temática centrada na questão da Cultura e Arte barroca e suas variadas nuances, tratadas como subassuntos ou assuntos secundários.

\section{O CECAB E O PATRIMÔNIO CULTURAL: CONTRIBUIÇÕES}

Criado em 1985 como um curso de pósgraduação do Instituto de Filosofia, Artes e Cultura da Universidade Federal de Ouro Preto, o CECAB objetivava promover o estudo crítico sobre as abordagens contemporâneas a respeito das manifestações culturais e artísticas luso-brasileiras dos séculos XVII, XVIII e XIX, e oferecer formação intelectual em nível de especialização, de caráter informativo e reflexivo sobre Cultura e a Arte barroca. Além disso, o curso pretendia contribuir, com subsídios teórico-metodológicos, para uma efetiva participação da UFOP na análise e na preservação do patrimônio artístico-cultural de Minas Gerais, inclusive com o propósito de se criar um Núcleo de Estudos Superiores sobre o Barroco em Ouro Preto ${ }^{10}$, com cursos de mestrado e doutorado na área.

Caracterizado como pioneiro do gênero no Brasil, o curso contou, durante todo o seu período de existência, com um corpo docente de excelência, formado por especialistas em assuntos diversos relativos ao Período Colonial Brasileiro, dentre eles os professores Moacyr Laterza (UFMG), Sônia Viegas (UFMG), Myriam Ribeiro de Oliveira (UFRJ), Ivo Porto de Menezes (UFMG), Hygina Bruzzi de Melo (UFMG), Júnia Ferreira Furtado (UFMG), Caio Boschi (PUC/MG), Ana Maria de Almeida (UFOP), Dalton Pedro Sala Júnior (Pinacoteca de SP), Alcir Pécora (UNICAMP), Carlos Antônio Leite Brandão (IPHAN), Adalgisa Arantes Campos (UFMG), Francisco Eduardo de Andrade (UFOP), Sérgio Alcides (UFMG), Elisa Freixo (Musicista), João Adolfo Hansen (USP), Marcos Hill (UFMG), Guiomar de Grammont (UFOP), e muitos outros professores e pesquisadores reconhecidos no meio acadêmico e intelectual no Brasil e no exterior.

${ }^{10}$ LATERZA, Moacyr. Ouro Preto: Centro de Estudos Avançados de Cultura e Arte Barroca.
O curso funcionava em regime modular, nos meses de janeiro e julho, com densa carga horária de 8 horas/aula diárias e agenda de visitação aos principais monumentos e sítios históricos mineiros, como Mariana, Ouro Preto, Congonhas, São João Del Rey, Tiradentes. Porém, a agenda agregava, também, alguns locais que abrigam importantes monumentos e obras barrocas, que são pouco conhecidos nos roteiros turísticos, como Santa Rita Durão, Catas Altas, Itaverava, Ouro Branco e os antigos distritos da região de Ouro Preto e Mariana. Estas atividades possibilitavam uma proximidade maior com os monumentos, acervos e obras barrocas e o contexto onde estão inseridas, oferecendo ao aluno a oportunidade de estar frente a frente ao objeto artístico, de observá-lo e conhecê-lo in loco, com orientações de professores especialistas em diversos aspectos e abordagens da arte e da cultura barroca.

O conteúdo programático era dividido em disciplinas, garantindo-se os princípios teóricos básicos que fundamentaram o curso, ou seja, a Filosofia da Arte, Estética do Barroco, Arte do Período Colonial, incluindo a Arquitetura, Pintura, Escultura, Literatura e Música, Sociedade Brasileira do Período Colonial, História e utilização contemporânea das cidades coloniais, agregando-se, também, nesta formação a dimensão de pesquisa com a disciplina de Metodologia da pesquisa. Durante o mês de julho, quando acontece o Festival de Inverno de Ouro Preto, eram agregados os seminários e palestras relacionadas às questões do patrimônio cultural, onde os alunos tinham a oportunidade de participar e conhecer artistas e intelectuais, brasileiros e estrangeiros, que participavam do evento.

Estas características do CECAB, somadas ao nível de excelência do corpo docente e ao fato do curso acontecer em Ouro Preto, uma cidade Patrimônio Cultural da Humanidade, considerada como um laboratório do barroco brasileiro, contribuíram para que o curso atraísse pessoas de diversas partes do país, mais precisamente de 17 estados, e alguns do exterior.

De acordo com os dados mapeados, muitos alunos eram profissionais que vinham com

Revista do IFAC, Ouro Preto, n.0, jan. 1987, p. 411. 
uma sólida bagagem de experiência na área do patrimônio cultural, e atuavam em instituições como o IPHAN, IEPHA, Fundação Nacional Pró-Memória, ou profissionais autônomos da área de restauração, que ocupavam cargos de gestão patrimonial e já eram portadores do título de Especialização e de Mestrado, em busca de ampliação de seus conhecimentos. Participaram do curso, também, muitos profissionais vinculados às instituições de Ouro Preto e Mariana, professores e funcionários da UFOP, do Museu da Inconfidência, da Casa dos Contos, do IPHAN, de museus, arquivos e outras instituições locais.

A confluência de todos os fatores mencionados anteriormente tornou-se um fator distintivo e qualificativo do curso, pois ele proporcionava um ambiente incomum de reunião de saberes, de trocas de conhecimentos e de experiências, de profusão de ideias, de profissionais diversos, tornando o $\mathrm{CECAB}$ um espaço diferenciado na formação de especialistas com visões mais críticas e questionadoras sobre o conceito de "Barroco", que constitui grande parte do patrimônio cultural brasileiro.

\subsection{AS MONOGRAFIAS DO CECAB}

Analisamos as 200 (duzentas) monografias que estão depositadas na Biblioteca do IFAC e destacamos as informações relevantes encontradas nos títulos, resumos, palavraschaves, conclusões e, quando necessário, ao texto integral. A indexação dos assuntos trata a grande variedade de temas que foram abordados nessas pesquisas, centrados na questão da Cultura e Arte barroca nas suas mais variadas nuances, que são descritos como sub-assuntos, ou assuntos secundários. $\mathrm{O}$ gráfico abaixo mostra os assuntos mais abrangentes e reincidentes das monografias do CECAB:

Gráfico 1: Área de conhecimento (assuntos) das monografias em porcentagem

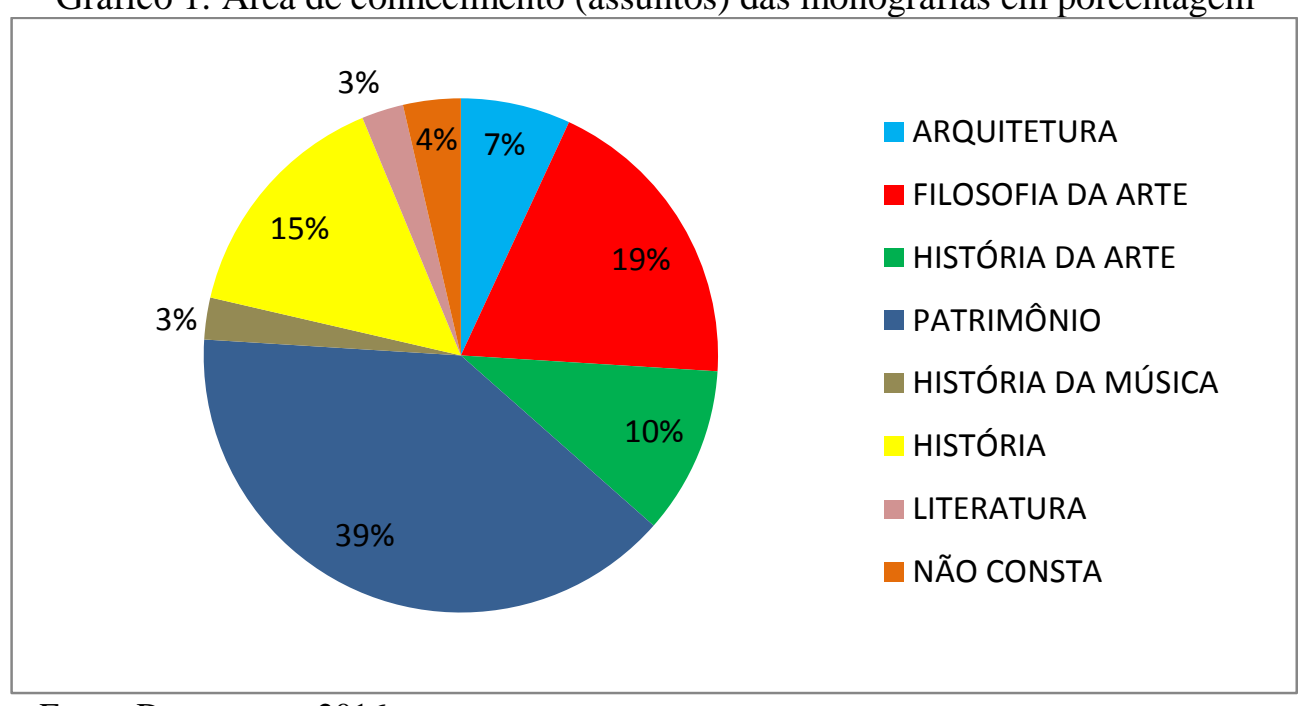

Fonte: Das autoras, 2016

Ressaltamos que por tratar da indexação dos assuntos gerais, estão agrupadas na terminologia Patrimônio todas as monografias que tratam do patrimônio nas suas mais variadas modalidades, como patrimônio cultural, histórico, artístico, preservação, restauração, educação patrimonial, legislação patrimonial, etc. Os demais assuntos são interrelacionados com a questão patrimonial, mas possuem um foco específico em áreas afins, estabelecidas na escolha do objeto da pesquisa.

Em continuidade e em termos de dinâmica da pesquisa julgamos pertinente verificar a concentração dos chamados assuntos geográficos, que na linguagem técnica da área de Biblioteconomia, quer dizer, de maneira geral, a localização geográfica da qual se trata uma pesquisa, ou onde está localizado o objeto da pesquisa. Esta vertente da investigação foi feita para verificar o pressuposto de que o aluno do CECAB, ao vir para Ouro Preto, trazia uma questão problemática de sua localidade de origem para ser investigada durante o seu trabalho de pesquisa, ou seja, o seu objeto de pesquisa. O resultado do estudo confirmou o nosso pressuposto e mostrou que 
o número das localidades encontradas nos assuntos geográficos das monografias é, praticamente, o mesmo número dos estados de origem dos alunos do curso, ou seja, 16 (dezesseis) estados, o que evidencia que o aluno serviu-se do curso para estudar e pesquisar uma questão existente na sua cidade ou estado de origem.

Vale ainda apontar que este resultado mostra, também, que a abrangência geográfica das pesquisas significa o alcance do curso em nível nacional, ao possibilitar estudos de localidades, assuntos e monumentos até então desconhecidos em termos de patrimônio cultural, que foram revelados a partir das investigações feitas por alunos do CECAB.

Outra variável constatada nesta etapa da análise de dados é que das 73 (setenta e três) monografias que trataram de temas relativos ao estado de Minas Gerais, o que era previsível, pois é o estado onde se tem a maior concentração de cidades históricas, monumentos e acervos do Período Colonial brasileiro. Explicitando melhor, esse cabeçalho de assunto identifica a localização do objeto de estudo da monografia, que pode ser uma igreja, uma obra de arte, o conjunto tombado, o traçado urbanístico, um artista local, etc., ou a própria localidade. O objetivo era identificar a abrangência regional das pesquisas iniciadas a partir do curso, em termos de avanços sobre os estudos do patrimônio cultural.

Refinando um pouco mais a análise destaca-se o detalhe do gráfico evidenciando que das 73 (setenta e três) monografias que tratam de temas localizados em Minas Gerais foram identificadas 24 (vinte e quatro) pesquisas que tratam de Ouro Preto, 9 (nove) sobre Mariana e 4 (quatro) são estudos que agregam os municípios de Ouro Preto e Mariana. As demais, ou seja, 22 (vinte e duas) foram pesquisas sobre outras cidades mineiras e 14 (quatroze) que abordam Minas Gerais como um todo, conforme mostra o Gráfico 2.

Gráfico 2: Assuntos-geográficos das monografias:

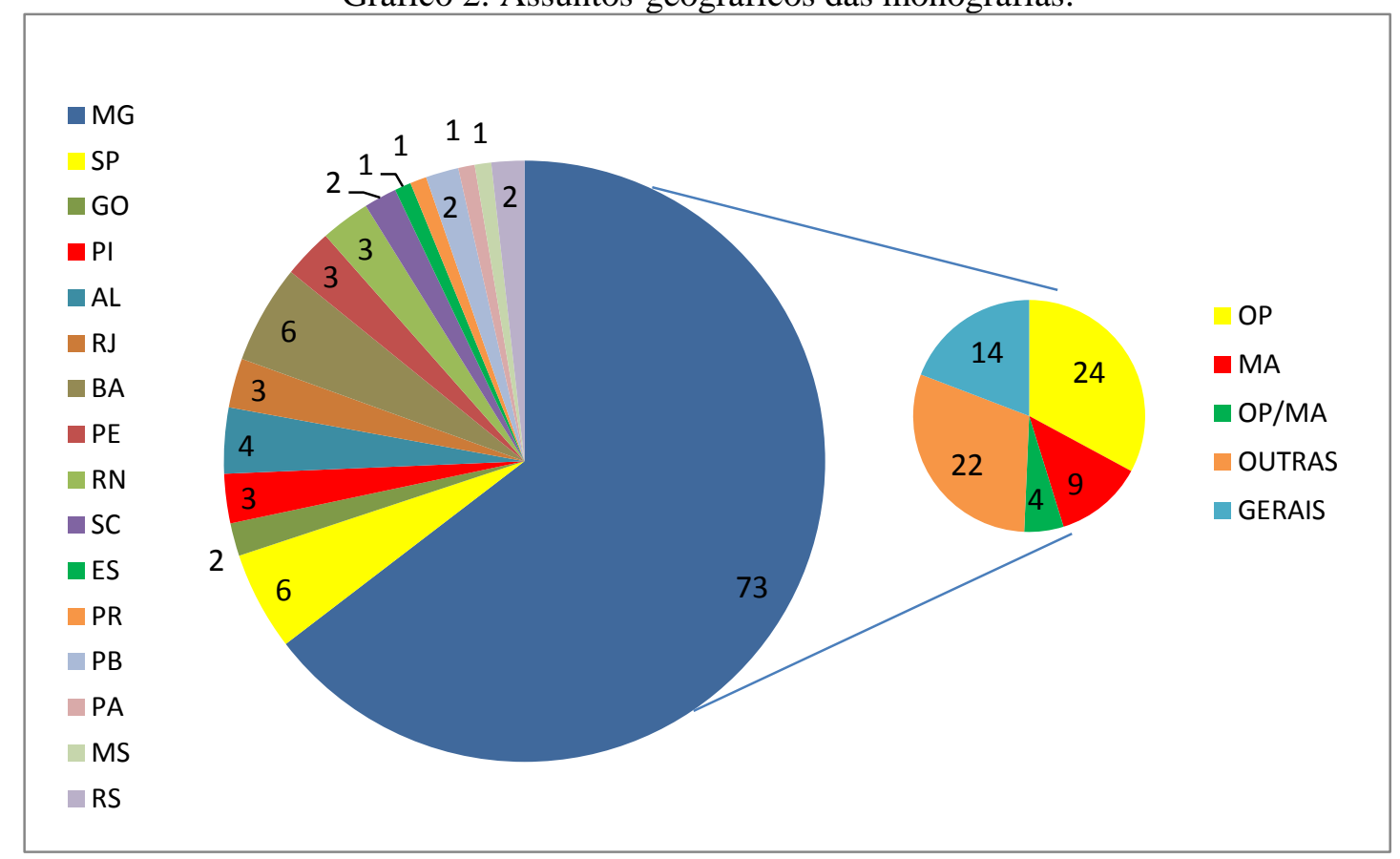

Fonte: Das autoras, 2016

No nosso entendimento, este enfoque da pesquisa revela a contribuição do $\mathrm{CECAB}$ para o estudo das questões relativas ao patrimônio cultural brasileiro, alguns inclusive inéditos, ou seja, sendo abordados e conhecidos pela primeira vez no meio acadêmico, através das pesquisas realizadas para a elaboração das monografias. Na a opinião de uma professora e gestora do curso:

As monografias foram os aspectos mais positivos, eu diria. Foram produzidas 
monografias sobre os mais diferentes aspectos da cultura e da arte barroca do Brasil, não só dos monumentos, do patrimônio artístico, mas também o patrimônio imaterial do Brasil foi abordado nessas pesquisas. Então, os benefícios, as contribuições para a cultura brasileira desse curso eram enormes! (Trecho da entrevista de Guiomar de Grammont, 2016)

\subsection{A EVOLUÇÃO DAS PESQUISAS}

Em etapa subsequente investigamos quais pesquisas tiveram início no trabalho de elaboração das monografias do $\mathrm{CECAB}$ e prosseguiram no contexto de formação em nível de mestrado e doutorado, ou foram publicadas como livros. Entendemos que os resultados desta etapa, sob outra perspectiva, retratam e agregam outros aspectos contributivos do curso para a geração de novos conhecimentos, pois os estudos realizados para as monografias estimularam a continuidades das pesquisas, inclusive em programas de pósgraduação de outras instituições.

O trabalho de levantamento de dados nesta fase se deu por meio da identificação do montante de monografias e de seus autores. Primeiramente foram identificados os autores a partir da listagem das monografias do CECAB, e em seguida, foi feita a comparação de equivalência dos títulos e das palavras chaves existentes nas três categorias de pesquisas, ou seja, nas monografias, dissertações e teses. Concluída esta etapa foram feitas as análises dos resumos e sumários das monografias e a equiparação com os demais trabalhos identificados. Recorremos, quando necessário, à leitura dos textos das publicações, como forma de garantir a confiabilidade das informações. A identificação dos títulos de livros que foram publicados a partir das temáticas das monografias foi feita por meio da investigação no Curriculum Lattes dos autores, e equiparados com os resumos das monografias.

A análise dos resultados mostrou que dentre as 200 (duzentas) monografias de conclusão de curso do CECAB 36 (trinta e seis) evoluíram em pesquisas mais aprofundadas e abrangentes, foram transformadas em dissertações, teses e livros, totalizando 48 (quarenta e oito) novas pesquisas, dentre elas, 4 (quatro livros) publicados. Detalhando um pouco mais, foram identificadas 22 (vinte e duas) que se tornaram dissertações, oito que se transformaram em dissertações e teses, duas que evoluíram como teses, três como dissertações e livros e um livro que foi publicado a partir da monografia. Do total das 10 (dez) teses de doutorado três delas foram defendidas em instituições estrangeiras. O Gráfico 3 sintetiza estes resultados:

Gráfico 3: Evolução das monografias:

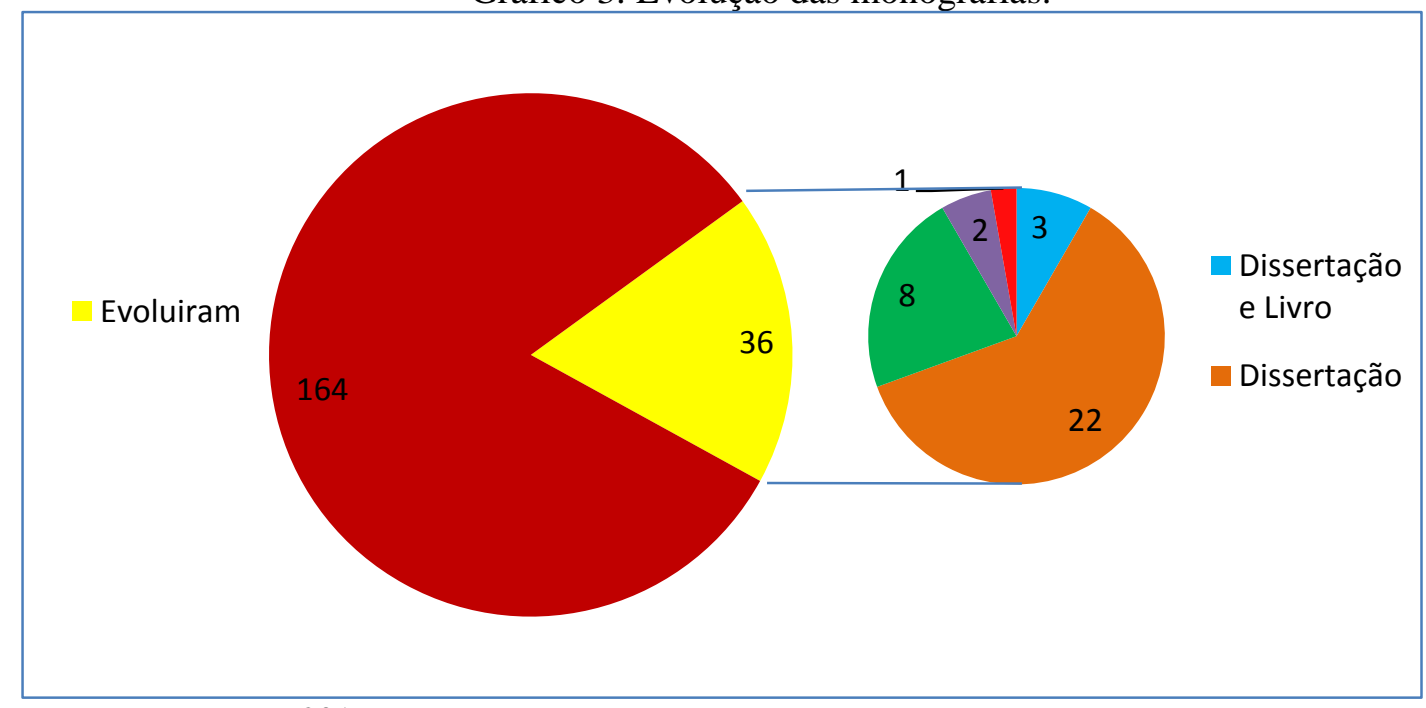

Fonte: Das autoras, 2016 


\section{CONSIDERAÇÕES FINAIS}

Ao finalizarmos esta pesquisa compreendemos que diversos fatores determinaram o nível de qualidade do CECAB, incluindo a excelência do corpo docente, o conteúdo programático, as metodologias de ensino utilizadas, as condições oferecidas pela ambientação em um sítio histórico tido como um laboratório temático, a formação acadêmica e a experiência profissional dos alunos, constituindo, assim, uma conjuntura favorável para o desenvolvimento de pesquisas relevantes. Não obstante as vicissitudes enfrentadas durante $\mathrm{o}$ período de funcionamento, o curso tornou-se referência na área do patrimônio cultural, qualificando profissionais e produzindo novos conhecimentos.

A análise das monografias evidenciou que muitas delas se destacam pelo aprofundamento na abordagem temática, pelo cuidado com o tratamento metodológico e, principalmente, pela originalidade, pois grande parte das pesquisas trata de assuntos, localidades, objetos e enfoques inéditos, pouco conhecidos no meio acadêmico. Verificamos que boa parte dos autores era de profissionais que possuíam experiência em atividades ligadas às áreas da cultura e do patrimônio cultural e a monografia foi uma oportunidade para o estudo de problemas de suas instituições, de suas localidades de origem. Esta característica, na nossa avaliação, marcou o diferencial dos trabalhos e das pesquisas realizadas para a elaboração das monografias, algumas de nível qualificativo avançado, com recomendações dos orientadores para serem convertidas em dissertação de mestrado. São estudos reveladores sobre capelas, imagens sacras, altares, igrejas, arquitetura civil, monumentos, museus, arquivos, sítios históricos, etc. e reflexões sobre a cultura predominante nos séculos XVIII e XIX, como as irmandades religiosas, festas populares, comportamentos sociais, dentre outros, incluindo localidades pouco conhecidas, principalmente pequenas cidades e distritos rurais que abrigam resquícios da arte e da cultura do Período Colonial.

Em termos conjunturais, tratando-se da diversidade temática, da abrangência geográfica e da propulsão para continuidade e desenvolvimento de novas pesquisas, concluímos que as monografias do CECAB podem ser consideradas como fontes de informação de referência para pesquisadores e interessados na área da Cultura e da Arte barroca. O resultado da investigação sobre novas pesquisas que foram originadas a partir de monografias iniciadas no CECAB foi positivo, pois mostrou que o curso constituiu em um elemento propulsor para $\mathrm{o}$ desenvolvimento de pesquisas em níveis mais significativos, capaz de despertar o interesse de alunos para a pesquisa científica e fomentar a preparação de novos pesquisadores.

$\mathrm{O}$ mapeamento das pesquisas que evoluíram posteriormente mostra que o curso foi capaz de estimular a continuidade de investigações, de aprofundar a busca de novas informações e de encontrar possibilidades e respostas para os problemas relativos ao patrimônio material e imaterial.

Sendo assim, os resultados da pesquisa revelaram que o CECAB da UFOP foi um curso significativo em termos de contribuição para o desenvolvimento científico, pois agregou novos conhecimentos para a área $\mathrm{e}$ estimulou a formação de pesquisadores e a produção de pesquisas no âmbito da Cultura e da Arte barroca. Em termos fundamentais, além de capacitar um grande número de especialistas de várias regiões do país para atuarem junto ao campo do patrimônio cultural brasileiro, o curso contribuiu para evidenciar estudos sobre culturas, localidades, monumentos e obras de arte pouco conhecidas e divulgadas no meio científico e acadêmico.

Recebido em: 27/10/2016

Aceito em definitivo em: 31/05/2017 


\section{Abstract}

This article corresponds to the partial result of the research and analysis of the Specialization Course in Baroque Art and Culture (CECAB), offered by the Federal University of OuroPreto, Brazil (UFOP). The theoretical contribution has been based on three fundaments - the concept of the Baroque Heritage and Culture, essential for the understanding of the purpose of the research; the constitution of the Memory as a sedimentation area for the knowledge; and the purpose of the Information Science as a space for the construction and interlocution of memory tales. In this snippet of research the object was to investigate, analyze and clarify the information about the collection of monographs - written by the students as course final projects - learning about their part and contribution for the educational field, and also as a production of knowledge in the field of cultural heritage. The methodology consisted of the identification of the monographs and their authors, the study of the range of themes researched, and the investigation on the elaboration of those works, including books, which resulted from researches initiated during such works. The results show that 200 works have been produced with a variable range of approaches, when it takes to culture and art in Colonial Brazil, being that 36 of them later became masters and PHD researches or were published as books. The research showed the importance of CECAB for the training of specialists and scientific knowledge production on the Brazilian cultural heritage, contributing to the advancement of the reflections in this particular field.

Keywords: Information and memory: Cultural heritage; Institutional memory; Scientific knowledge; Baroque Culture and Art.

\section{REFERÊNCIAS}

ARARIPE, Fátima Maria Alencar. Do patrimônio cultural e seus significados. Transinformação, Campinas, v. 16, n. 12, p. 111-122, maio/ago. 2004.

ARAÚJO, Carlos Alberto Ávila. Correntes teóricas da Ciência da Informação. Ciência da Informação, Brasília, v. 38, n. 3, p. 192-204, set./dez. 2009.

BOSI, Ecléa. Memória e sociedade: memória de velhos. São Paulo: T. A. Queiroz, 179. 402p.

BOURDIEU, Pierre. Os ritos de instituição. In: . A economia das trocas linguísticas.

São Paulo: Edusp, 2008. p. 97-106.

CABRAL, Ana Maria Rezende. A Ciência da Informação, a cultura e a sociedade informacional. In: REIS, A. S. dos; CABRAL, A. M. R. (Orgs.). Informação, cultura e sociedade: interlocuções e perspectivas. Belo Horizonte: Novatus, 2007. p. 29-47.
CARDOSO, Ana Maria. Pós-modernismo e informação: conceitos complementares? Perspectivas em Ciência da Informação, Belo Horizonte, v. 1, n. 1, p. 63-79, jan./jun. 1996.

CARDOSO, Ana Maria. Retomando possibilidades conceituais: uma contribuição do campo da Informação Social. Ver. Esc. Biblioteconomia UFMG, Belo Horizonte, v.23, n.2 p. 104-114, jul./dez. 1994.

FUNARI, Pedro Paulo Abreu; PELEGRINI, Sandra de Cássia Araújo. Patrimônio histórico e cultural. Rio de Janeiro: Jorge Zahar, 2006. $72 \mathrm{p}$

HALBWACHS, Maurice. A memória coletiva. São Paulo: Centauro, 2006. 224 p.

LE GOFF, Jacques. História e memória. 5. ed. São Paulo, Ed. Unicamp, 2003. 541 p.

MARCONI, M. A.; LAKATOS, E. M. Técnicas de pesquisa. 2. ed. São Paulo, Atlas, 1990. 
NORA, Pierre. Entre memória e história: a problemática dos lugares. Projeto História. São Paulo, v. 10, dez. 1993. p. 07-28.

REIS, Alcenir Soares dos; CABRAL, Ana Maria Rezende (Org.). Informação, cultura e sociedade: interlocuções e perspectivas. Belo Horizonte: Novatus, 2007. 144p.

REIS, Alcenir Soares dos. Informação e patrimônio cultural: aproximações. In: REIS, A. S. dos; FIGUEIREDO, B. G. (orgs). Patrimônio imaterial em perspectiva. Belo Horizonte: Fino Traço, 2015. p. 107-125.

SANTOS, Mariza Velloso Mota. O tecido do tempo: a ideia de patrimônio cultural no Brasil,
1920-1970. 1992. 47 f. Tese (Doutorado em Antropologia) - Universidade de Brasília, 1992.

SHIKIDA, Aparecida Maciel da Silva. Informação, história e memória: a constituição social da informação em relatos orais. 2005. 157 f. Dissertação (Mestrado em Ciência da Informação) - Escola de Ciência da Informação, UFMG, Belo Horizonte, 2005.

THIESEN, Icléia. Memória institucional: a construção conceitual numa abordagem teórico-metodológica. 1997. 169 f. Tese (Doutorado em Ciência da Informação) IBICT, Rio de Janeiro, 1997. 